\title{
The Road to Molecular Metal Wires: The Past and Recent Advances of Metal String Complexes
}

\author{
${ }^{a}$ Department of Chemistry and Center for Emerging Material and Advanced Devices, National \\ Taiwan University, Taipei, Taiwan \\ ${ }^{\mathrm{b}}$ Institute of Chemistry, Academia Sinica, Taipei, Taiwan \\ Isiah Po-Chun Liu, ${ }^{a}$ Chun-hsien Chen, ${ }^{a}$ and Shie-Ming Peng*a,b \\ Received August 19, 2011; E-mail: smpeng@ntu.edu.tw
}

\begin{abstract}
The revisit of $\mathrm{Ni}_{3}(\mathrm{dpa})_{4} \mathrm{Cl}_{2}\left(\mathrm{dpa}^{-}=\right.$dipyridylamido anion) by the groups of Hathaway, Cotton, and ours in the early $1990 \mathrm{~s}$ extended the knowledge of metal-metal bonds beyond dinuclear metal complexes and started the journey of metal string complexes. The typical conformation of metal string complexes consists of a one-dimensional oligonuclear transition metal backbone supported by four organic ligands. Because of this novel geometry, metal string complexes can provide great insight into multiple metal-metal bonds, and may have potential applications as molecular wires. This field therefore has grown significantly in the past 20 years and continues to be an attractive and dynamic area of study. In this review, we will firstly describe the origin of this research field. Important properties associated with the multinuclear metal-metal multiple bonding such as the variety in types of metal cores and molecular lengths, electronic configurations, magnetic properties, and the efficiency of electron-transport through the metal strings will be introduced. Finally, two new generations of metal string complexes, mixed-valence nickel string complexes and heteronuclear metal string complexes, will be introduced. Mixed-valence nickel string complexes contain mixed-valent $\left[\mathrm{Ni}_{2}(\text { napy })_{4}\right]^{3+}$ units, which show about $40 \%$ enhancement of the conductance in comparison with those of typical nickel string complexes. Moreover, the insertion of a heteronuclear metal ion in a homonuclear metal string complex provides a new way of tuning its physical properties, which is a potential approach to build bio-mimics and inorganic electronic devices. This review will aim to provide readers with general understanding of the past results and future challenges of this research field.
\end{abstract}

\section{Introduction}

In the past several decades, there has been a nearly exponential growth in the capabilities of silicon semiconductors. ${ }^{1)}$ With the miniaturization of transistors on silicon semiconductors, chips come with faster processing speeds which are resulting in more powerful computational systems. Nowadays, the routine commercial size of semiconductor chips has been dramatically reduced to almost $100 \mathrm{~nm}$. Although a further decrease is likely, once the size of circuits becomes $<10 \mathrm{~nm}$, several quantum limitations may trouble the performance of solid state devices. Furthermore, the extremely expensive cost of minimization could also severely retard the industry, and it is possible that silicon semiconductors may not be used in the forthcoming era of nanoelectronics. ${ }^{2)}$

Due to the above reasons, new materials for use in computer architectures should be developed and considered. Molecular electronic devices are therefore one of the outstanding candidates because of their potential application as key components in future computational devices. ${ }^{2,3)}$ Molecular electronic devices are fabricated from single or small packets of molecules, which have the advantage of being $10^{6}$ times smaller than current silicon-based devices. ${ }^{2 a)}$ By the use of suitable synthetic methods, various molecular electronic devices could be created for a variety of purposes. Moreover, the cost for synthesizing molecular electronic devices is cheaper in comparison to the fabrication process of conventional semiconductors.

The simplest and most fundamental electronic components of molecular electronic devices are molecular wires. The reason for such attractiveness is clear, since wires, in our world, are used widely to assemble any type of electronic devices. The general feature of molecular wires is a linear molecule that is able to mediate charge transport over long distance. ${ }^{4)}$ In other words, they are expected to connect to two electrodes in order to provide a conductive path for electrons.

Among the molecular wires, a branch of complexes which consists of a 1D linear transition metal backbone is of special interest. These complexes, which possess continuous metal wire-like backbones, are similar to the electric wires in our macroscopic world, and electrons are expected to transfer 
directly through the wire-like framework. The pioneer compound in this family, "Krogmann's salt", was firstly reported in 1969.5) The basic unit of the Krogmann's salt is a square-planar $\left[\mathrm{Pt}(\mathrm{CN})_{4}\right]^{\mathrm{n}-}(\mathrm{n} \sim 1.7)$ anion. These anions then stack by means of the overlap of the $\mathrm{d}_{\mathrm{z}^{2}}$ orbitals, which form an infinite chain (Scheme 1). The Krogmann's salt exhibits metallic luster and high conductivity possibly due to the partial Pt-Pt bond formation. ${ }^{\text {) }}$
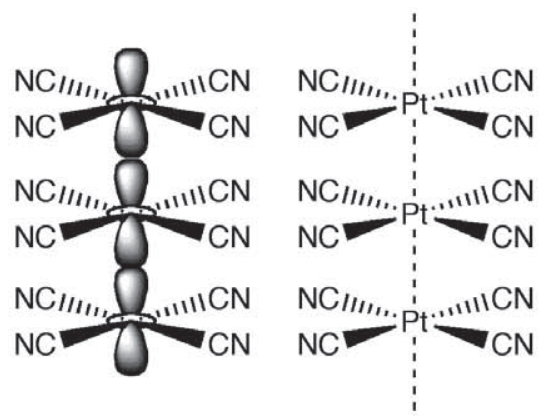

Scheme 1 Krogmann's salt.

After the discovery of Krogmann salt, the development of 1D metal chain complexes has been prosperous in the past forty years. ${ }^{6 \mathrm{~d}, 7)}$ In this regard, our lab aimed to design and study the linear metal chain complexes supported by four oligopyridylamine ligands (Scheme 2), ${ }^{8}$ and the history of our research in this field will be described throughout this review.

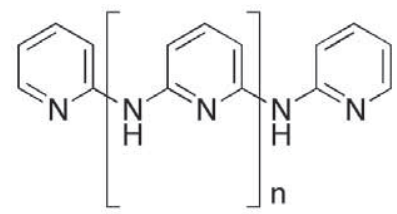

Scheme 2 Oligopyridylamine ligands

\section{Metal string complexes (Extended metal atom chains)}

The history of metal string complexes can be traced back to the synthesis of $\mathrm{Ni}_{3}(\mathrm{dpa})_{4} \mathrm{Cl}_{2}$ (dpa $=$ dipyridylamido anion $)$ in 1968.9) At that time, this compound was proposed to contain a paramagnetic trinickel core. However, its structure was not determined correctly. After 20 years, the exact structure of this complex was finally reported by Hathaway et al. ${ }^{10)}$ The correct structure of $\mathrm{Ni}_{3}(\mathrm{dpa})_{4} \mathrm{Cl}_{2}$ shows that this molecule consists of a linear $\mathrm{Cl}-\mathrm{Ni}-\mathrm{Ni}-\mathrm{Ni}-\mathrm{Cl}$ chain, surrounded by four dpa- ligands (Figure 1). Because of this novel geometry, $\mathrm{Ni}_{3}(\mathrm{dpa})_{4} \mathrm{Cl}_{2}$ and its analogue, $\mathrm{Cu}_{3}(\mathrm{dpa})_{4} \mathrm{Cl}_{2}$, caught our attentions in the middle of the 1990s. Our group then began to synthesize and study similar compounds, $\mathrm{M}_{3}(\mathrm{dpa}){ }_{4} \mathrm{Cl}_{2}(\mathrm{M}=\mathrm{Co}, \mathrm{Cr}, \mathrm{Ru}$ and $\mathrm{Rh}){ }^{8}{ }^{8}$ After our successful synthesis of these trinuclear compounds, Professor F. A. Cotton and his group engaged in the study of the physical properties of such compounds, providing many valuable insights into this field. $\left.{ }^{4 a}, 8 c\right)$

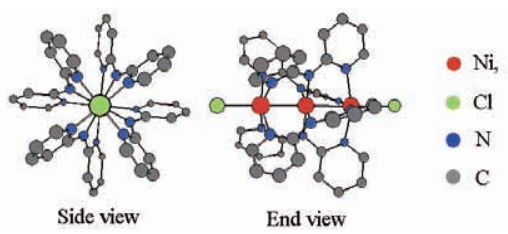

Fig. 1 Molecular structure of the $\mathrm{Ni}_{3}(\mathrm{dpa})_{4} \mathrm{Cl}_{2}$.

As mentioned above, the amido and pyridino groups of the dpaligand can efficiently stabilize the central linear trinuclear metal core ${ }^{8 b)}$ In order to synthesize longer linear oligonuclear metal complexes, a rational method is to extend the length of the dpa ligand. Based on this idea, we had coupled amino- and chloropyridines by palladium-catalyzed cross coupling. ${ }^{8 b}$ B By using the new longer oligopyridylamido ligands, a number of pentametal complexes $\left[\mathrm{M}_{5}\right.$ (tpda) $\left.{ }_{4} \mathrm{Cl}_{2}\right]\left(\mathrm{M}=\mathrm{Ni}^{\mathrm{II}}, \mathrm{Co}^{\mathrm{II}}, \mathrm{Cr}^{\mathrm{II}}\right.$ and $\mathrm{Ru}^{\mathrm{II}}$, tpda ${ }^{2-}$ $=$ tripyridyldiamido), ${ }^{11)}$ heptametal complexes $\left[\mathrm{M}_{7}\right.$ (teptra) $\left.{ }_{4} \mathrm{Cl}_{2}\right]$ $\left.\left(\mathrm{M}=\mathrm{Ni}^{\mathrm{II}} \text { and } \mathrm{Cr}^{\mathrm{II}} \text {, teptra }{ }^{3-}=\text { tetrapyridyltriamido }\right)^{12}\right)$ and nonametal complexes $\left[\mathrm{M}_{9}\right.$ (peptea) $\left.{ }_{4} \mathrm{Cl}_{2}\right]\left(\mathrm{M}=\mathrm{Ni}^{\mathrm{II}}\right.$ and $\mathrm{Cr}^{\mathrm{II}}$,

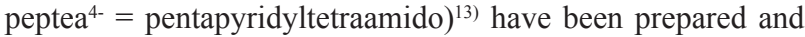
characterized (Scheme 3). Since all these compounds contain a linear oligonuclear transition metal framework, our group chose the terminology "Metal String Complexes" whilst Cotton used "Extended Metal Atom Chains (EMACs)" ${ }^{8)}$
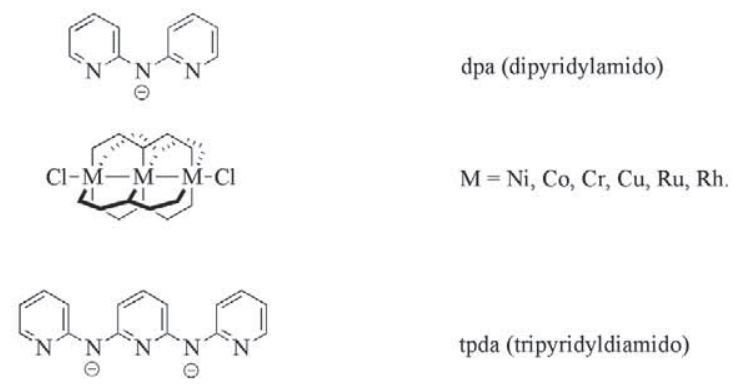

tpda (tripyridyldiamido)

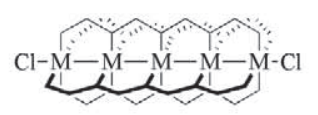

$\mathrm{M}=\mathrm{Ni}, \mathrm{Co}, \mathrm{Cr}$.

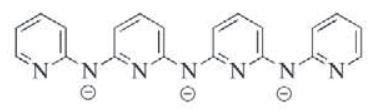

teptra (tetrapyridyltriamido)

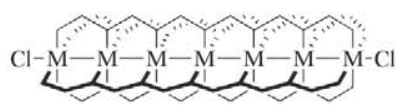

$\mathrm{M}=\mathrm{Ni}, \mathrm{Cr}$.

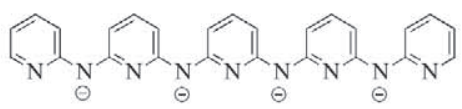

peptea (pentapyridyltetraamido)

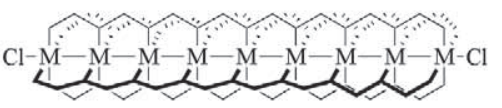

$\mathrm{M}=\mathrm{Ni}$

Scheme 3 Oligonuclear metal string complexes. The structures of these metal string complexes consist a linear transition metal framework helically wrapped by four ligands. 


\section{Electronic structures and metal-metal bonds of metal string complexes}

Paddlewheel dinuclear transition metal compounds are great examples for studying metal-metal bonds. ${ }^{14)}$ Since metal string complexes also show paddlewheel geometries, the presence of more metal ions significantly extend the scope of metal-metal bonds. Therefore, research interests of metal string complexes initially focused on the study of multinuclear multiple metalmetal bonds. $\left.{ }^{4 a}, 15\right)$

In order to realize the bonding situation in metal string complexes, the reader should have fundamental understanding of their electronic structure. Since the electronic structures and metal-metal bonds of metal string complexes were reviewed by Berry in $2010,{ }^{8 c)}$ it will be introduced only briefly here. Let us first think about the electronic structures of trinuclear metal string complexes. In trinuclear metal string complexes, the $\mathrm{d}$ orbitals of the transition metals generate three types of molecular orbitals (Scheme 4): (1) $\sigma$-type $\operatorname{MOs}\left(\sigma, \sigma_{\mathrm{nb}}\right.$, and $\left.\sigma^{*}\right)$, composed of $\mathrm{d}_{\mathrm{z}^{2}}$ orbitals. (2) $\pi$-type $\operatorname{MOs}\left(\pi, \pi_{\mathrm{nb}}\right.$, and $\left.\pi^{*}\right)$, composed of $d_{x z}$ and $d_{y z}$ orbitals. (3) $\delta$-type $\operatorname{MOs}\left(\delta, \delta_{n b}\right.$, and $\left.\delta^{*}\right)$, composed of $\mathrm{d}_{\mathrm{xy}}$ orbitals. In principle, the interaction between $\mathrm{d}_{\mathrm{z}^{2}}$ orbitals is strongest while the interaction between $\mathrm{d}_{\mathrm{xy}}$ orbitals is weakest. Although the sequence of these three types of MOs may vary by interacting with different axial ligands, the MOs sequence of trimetal strings can be assigned qualitatively as $(\sigma)$ $(\pi)(\delta)\left(\sigma_{\mathrm{nb}}, \pi_{\mathrm{nb}}, \delta_{\mathrm{nb}}\right)\left(\delta^{*}\right)\left(\pi^{*}\right)\left(\sigma^{*}\right)$. The electronic configurations of these MOs resulting from various occupancies of $\mathrm{d}$ electrons then play a key role in determining the metal-metal bonds. For example, $\mathrm{Ni}_{3}(\mathrm{dpa})_{4} \mathrm{Cl}_{2}$ has $24 \mathrm{~d}$ electrons, which results in the electronic configuration, $(\sigma)^{2}(\pi)^{4}(\delta)^{2}\left(\sigma_{n b}, \pi_{n b}\right.$, $\left.\delta_{\mathrm{nb}}\right)^{8}\left(\delta^{*}\right)^{2}\left(\pi^{*}\right)^{4}\left(\sigma^{*}\right)^{2} .{ }^{16}$ ) Since all bonding and antibonding orbitals are fully occupied, the bond order ((number of bonding electrons - number of antibonding electrons) / 2) is 0 . There are no $\mathrm{Ni}-\mathrm{Ni}$ bonds in $\mathrm{Ni}_{3}(\mathrm{dpa})_{4} \mathrm{Cl}_{2}$. On the contrary, $\mathrm{Co}_{3}(\mathrm{dpa})_{4} \mathrm{Cl}_{2}$ has $21 \mathrm{~d}$ electrons, which confer the electronic configuration, $(\sigma)^{2}(\pi)^{4}(\delta)^{2}\left(\pi_{n b}, \delta_{n b}\right)^{6}\left(\delta^{*}\right)^{2}\left(\pi^{*}\right)^{4}\left(\sigma_{n b}\right)^{1} \cdot{ }^{15 a, 17)}$ In this case, the highest $\sigma$-antibonding orbital $\left(\sigma^{*}\right)$ is empty, which causes the bond order of $\mathrm{Co}_{3}(\mathrm{dpa})_{4} \mathrm{Cl}_{2}$ to be $1 . \mathrm{Co}_{3}(\mathrm{dpa})_{4} \mathrm{Cl}_{2}$ therefore provides a typical example of the delocalized threecenter metal-metal bonds. It should be noted that the above assignment only provides a fundamental insight into the metal-metal bonds in trinuclear metal string complexes. Some compounds exhibit unusual metal-metal bonds due to different metal-axial ligand interactions or structural distortions, and the most famous examples are $\mathrm{Ru}_{3}(\mathrm{dpa})_{4} \mathrm{X}_{2}(\mathrm{X}=\mathrm{Cl}$ or $\mathrm{CN})$ and $\mathrm{Cr}_{3}(\mathrm{dpa})_{4} \mathrm{Cl}_{2}{ }^{18)}$ For triruthenium complexes, the strength of the metal-metal bonds can be fine-tuned by replacing the axial ligands. When two weak field $\mathrm{Cl}^{-}$ions are coordinated to $\left[\mathrm{Ru}_{3}(\mathrm{dpa})_{4}\right]^{2+}$, the compound $\mathrm{Ru}_{3}(\mathrm{dpa})_{4} \mathrm{Cl}_{2}$ has the electronic configuration, $(\sigma)^{2}(\pi)^{4}(\delta)^{2}\left(\pi_{\mathrm{nb}}, \delta_{\mathrm{nb}}\right)^{6}\left(\delta^{*}\right)^{2}\left(\sigma_{\mathrm{nb}}\right)^{2}$, which results in the formation of one Ru-Ru $\sigma$-bond and two $\pi-R u-R u$ bonds. However, when $\left[\mathrm{Ru}_{3}(\mathrm{dpa})_{4}\right]^{2+}$ is bonded to two strong field $\mathrm{CN}^{-}$ ions, the $\pi$-acid $\mathrm{CN}^{-}$ligands stabilize the upper $\pi^{*}$ orbitals. The electronic configuration of $\mathrm{Ru}_{3}(\mathrm{dpa})_{4}(\mathrm{CN})_{2}$ is $(\sigma)^{2}(\pi)^{4}(\delta)^{2}\left(\pi_{\mathrm{nb}}\right.$, $\left.\delta_{\mathrm{nb}}\right)^{6}\left(\delta^{*}\right)^{1}\left(\pi^{*}\right)^{3}$. The metal-metal bonds in $\operatorname{Ru}_{3}(\mathrm{dpa})_{4}(\mathrm{CN})_{2}$ therefore becomes one Ru-Ru $\sigma$-bond, $0.5 \mathrm{Ru}-\mathrm{Ru} \pi$-bonds and $0.5 \mathrm{Ru}$-Ru $\delta$-bonds (Scheme 5). On the other hand, an unsymmetrical trichromium framework with $\mathrm{Cr}-\mathrm{Cr}$ distances of $2.24 \AA$ and $2.48 \AA$ was found in $\mathrm{Cr}_{3}(\mathrm{dpa})_{4} \mathrm{Cl}_{2}$. This unusual geometry leads to an unsymmetrical trichromium framework with localized $\left(\mathrm{Cr}_{2}\right)^{4+}$ quadruple bonds and an isolated $\mathrm{Cr}^{\mathrm{II}}$ ion (Scheme 6).

In addition to the trinuclear metal string complexes, metal-metal bonds in longer metal string complexes are also interesting. As the number of transition metal ions increases, different metal-metal contacts result in various kinds of multinuclear metal-metal bonds. Unfortunately, the study of metal-metal bonds in longer metal string complexes is still under developed as the large size of longer metal string complexes only allows us to analyze their metal-metal bonds by utilizing Hückel calculations. As the available computational resources become more powerful, it will be possible to realize the nature of metal-metal bonds of longer metal string complexes in the future, which should significantly extend the scope in the field of metal-metal bonds.

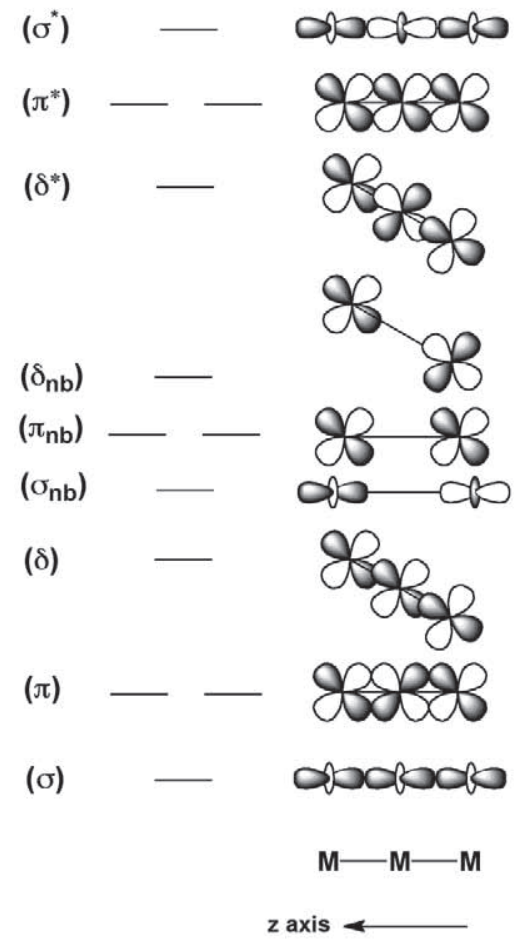

Scheme 4 Qualitative molecular orbitals sequence of trinuclear metal string complexes. 
<smiles>CCCCC</smiles>
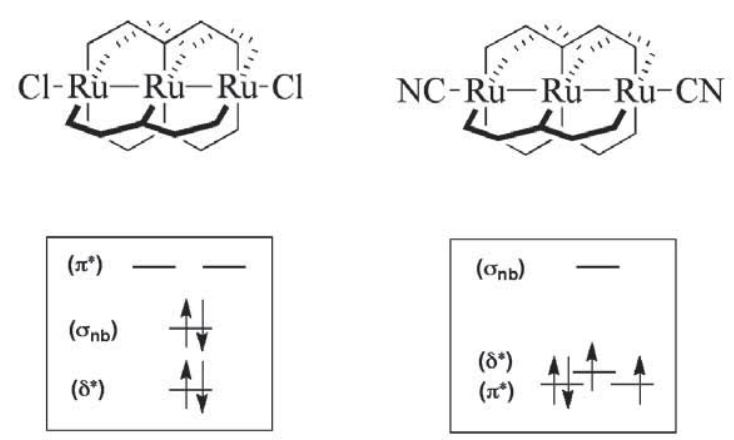

Scheme 5 Electronic configurations of $\mathrm{Ru}_{3}(\mathrm{dpa})_{4} \mathrm{Cl}_{2}$ (left) and $\mathrm{Ru}_{3}(\mathrm{dpa})_{4}(\mathrm{CN})_{2}$ (right).
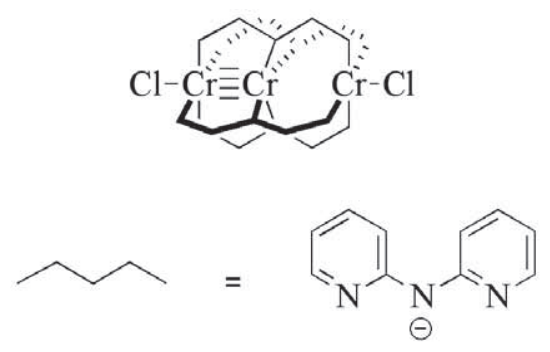

Scheme 6 Unsymmetrical $\mathrm{Cr}_{3}(\mathrm{dpa})_{4} \mathrm{Cl}_{2}$ complex.

\section{Metal string complexes function as molecular wires}

As the length of the linear metal chain complexes is elongated, the conformation of such complexes becomes close to the conventional electric wire we are familiar with. Cotton and Murillo provided an interesting suggestion regarding the relationship between metal string complexes and an electric wire in the macroscopic world. ${ }^{4 a)}$ In their perspective, the metal string complexes could be described as "a chain of single metal atoms with a proportionately thin layer of insulation (ligands)", which have the same form as the electric wire, and the order of magnitude of the reduction factor is $10^{-7}$ (Figure 2). Since the

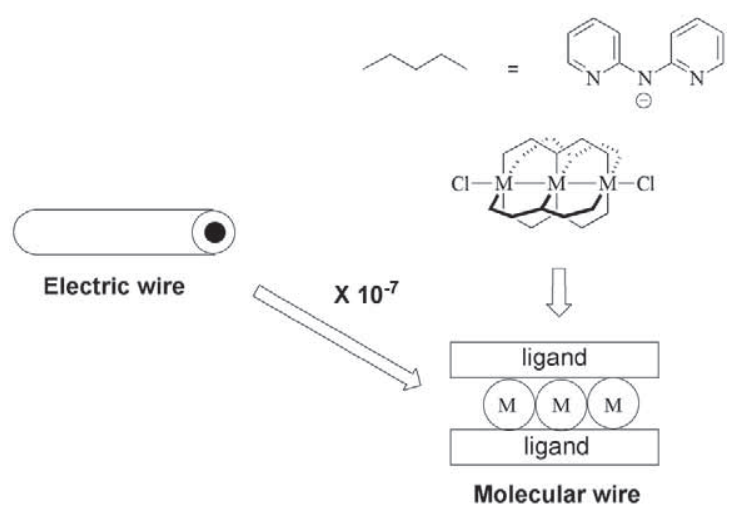

Fig. 2 An electric wire and a molecular wire suggested by Cotton and Murillo. metal string complexes may have potential to be future molecular wires, to probe their electron transport capability at the molecular level becomes an interesting project.

The first attempt to probe the electronic transport in metal string complexes was to use electrochemical methods. ${ }^{19)}$ The idea of this method is to use two redox-active ferrocenylacetylide termini connected to both ends of the metal string complexes (Scheme 7). By analyzing the difference between two one-electron oxidation waves of the ferrocene $(\mathrm{Fc})$ termini, the charge transfer through the bridging oligometal chain can be studied qualitatively. The difference in the oxidation potential for the two $\mathrm{Fc}$ sites in $\mathrm{Co}_{3}(\mathrm{dpa})_{4}(\mathrm{C} \equiv \mathrm{CFc})_{2}$ and $\mathrm{Ru}_{3}(\mathrm{dpa})_{4}(\mathrm{C} \equiv \mathrm{CFc})_{2}$ are $71 \mathrm{mV}$ and $100 \mathrm{mV}$, respectively, suggesting stepwise one-electron oxidations rather than a twoelectron oxidation. These values indicate charge transfer across the linear $\left[\mathrm{Co}_{3}(\mathrm{dpa})_{4}\right]^{2+}$ and $\left[\mathrm{Ru}_{3}(\mathrm{dpa})_{4}\right]^{2+}$ units, which show the desired properties of a molecular wire.<smiles>CCCCC</smiles>
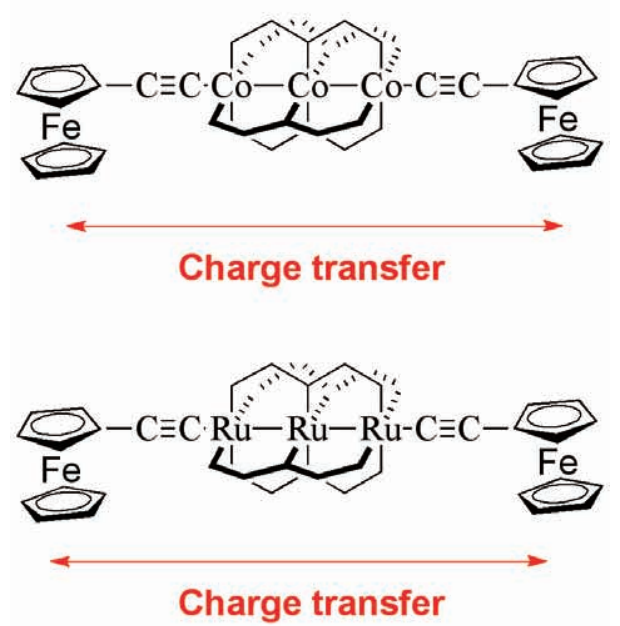

Scheme 7 Compounds $\mathrm{Co}_{3}(\mathrm{dpa})_{4}(\mathrm{C} \equiv \mathrm{CFc})_{2}$ and $\mathrm{Ru}_{3}(\mathrm{dpa})_{4}(\mathrm{C} \equiv \mathrm{CFc})_{2}$ with redox-active $\mathrm{Fc}$ at two terminals.

Although voltammetric studies indicate that the metal string complexes are efficient mediators of intramolecular charge transfer, there is still no direct evidence for electron transport properties in metal string complexes. In order to test the "real" electron-transfer (ET) efficiency of tri- and penta-nuclear metal strings, the STM-bj (scanning tunneling microscopy break junction) methodology was used. ${ }^{20)}$ Figure 3 shows a typical STM-bj experiment conducted on metal string complexes. A gold STM tip is repetitively impinged onto and retracted from the gold substrate in order to create molecular junctions where metal string complexes in the solvent of toluene spontaneously absorb via the terminal anchoring group (-NCS). The STMbj experiments show that the single molecular resistances 
(R) of $\mathrm{Ni}_{3}(\mathrm{dpa})_{4}(\mathrm{NCS})_{2}, \mathrm{Co}_{3}(\mathrm{dpa})_{4}(\mathrm{NCS})_{2}$ and $\mathrm{Cr}_{3}(\mathrm{NCS})_{4} \mathrm{Cl}_{2}$ are $3.4 \mathrm{M} \Omega, 1.9 \mathrm{M} \Omega$ and $0.9 \mathrm{M} \Omega$, respectively, which show wire-like characteristics. By studying the conductance of triand penta-nuclear metal strings, the STM measurements also suggest that the ET efficiency of metal strings is dependent on the extent of metal-metal bond order. In principle, the metal string complexes with the stronger metal-metal bonds exhibit the better conductivity. ${ }^{20)}$

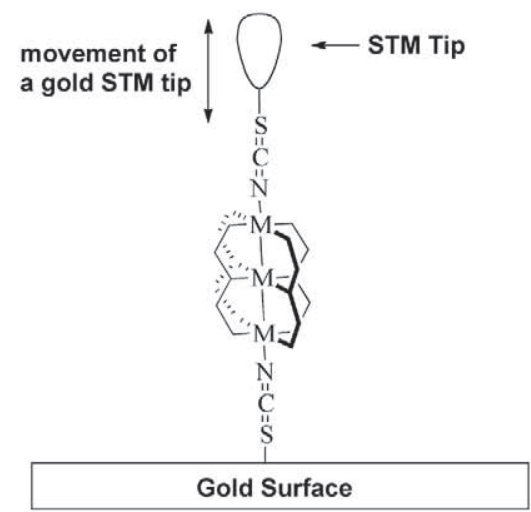

Fig. 3 Illustration of STM-bj experiment for measuring single molecular conductance.

\section{New generations of metal string complexes}

As more and more metal string complexes supported by oligopyridylamido ligands have been isolated and reported, the studies of metal string complexes seem to be maturing. How to effectively design new metal string complexes, therefore, becomes a new challenge in this field.

\subsection{Mixed-valence oligonickel string complexes}

In 2006, we reported our first success in synthesizing a 2,7-bis( $\alpha$-pyridylamino)-1,8-naphthyridine $\quad\left(\mathrm{H}_{2}\right.$ bpyany) ligand, which contains pyridyl and naphthyridyl groups (Figure 4). ${ }^{21)}$ Since the naphthyridyl group is electron-deficient, the less anionic naphthyridyl-modulated ligand, $\mathrm{H}_{2}$ bpyany, can not compensate the positive charges of the central oligonickel core as effectively as oligopyridylamido ligands do, resulting in a reduced mixed-valence (MV) $\left[\mathrm{Ni}_{2}(\text { napy) })_{4}\right]^{3+}$ unit within the hexanickel framework (Figure 4). Interestingly, by inserting the $\left.\left[\mathrm{Ni}_{2} \text { (napy) }\right)_{4}\right]^{3+}$ unit into the pentanickel framework, the MV pentanickel string complex, $\left[\mathrm{Ni}_{5}(\mathrm{bna})_{4}(\mathrm{NCS})_{2}\right](\mathrm{NCS})_{2}$ (bna $=$ bisnaphthyridylamido, Figure 5), shows about $40 \%$ enhancement of the conductivity in comparison with that of the typical homovalent pentanickel string, $\left[\mathrm{Ni}_{5}(\text { tpda })_{4}(\mathrm{NCS})_{2}\right]$ $\left(\right.$ tpda $^{2-}=$ tripyridyldiamido $\left.) .{ }^{22}\right)$ This great enhancement in conductance is attributed to the electron mobility within the mixed-valent pentanickel framework due to the formation of a partial $\sigma \mathrm{Ni}-\mathrm{Ni}$ bond in the $\left[\mathrm{Ni}_{2}(\text { napy) })_{4}\right]^{3+}$ unit. $^{23)}$

The MV $\left[\mathrm{Ni}_{2}(\text { napy })_{4}\right]^{3+}$ unit has been proven to be a practical tool to enhance the conductivity of metal string complexes. This exciting result indicates that the designation of naphthyridyl-modulated ligands is a rational approach to develop future novel metal string complexes. Therefore, numerous oligonickeal string complexes supported by various naphthyridyl-modulated ligands have been synthesized and reported in the past five years. ${ }^{24)}$ It is noteworthy that the longest metal string complex, $\left[\mathrm{Ni}_{11}\right.$ (tentra) $\left.{ }_{4} \mathrm{Cl}_{2}\right]\left(\mathrm{PF}_{6}\right)_{4}$ (tentra ${ }^{3-}$ $=\mathrm{N}^{2}$-(2-(1,8-naphthyridin-7-ylamino)-1,8-naphthyridin-7-yl)$\mathrm{N}^{7}$-(1,8-naphthy-ridin-2-yl)-1,8-naphthyridine-2,7-diamido, abbreviated as tetranaphthyridyl triamido) had recently been reported by our group (Figure 6). ${ }^{25)}$ This unprecedented giant metal string complex was also stabilized by naphthyridylmodulated ligands. The utilization of naphthyridyl-modulated ligands makes significant progress toward designing new metal string complexes, which not only improves the molecular conductance, but also elongates the length of metal string complexes, and thus is considered as an important landmark in this field.

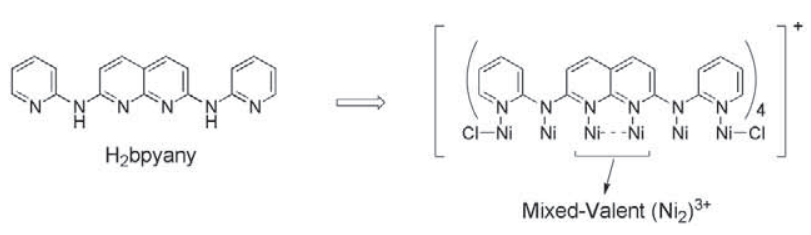

Fig. 4 The ligand $\mathrm{H}_{2}$ bpyany and a related mixed-valent hexanickel string compound.
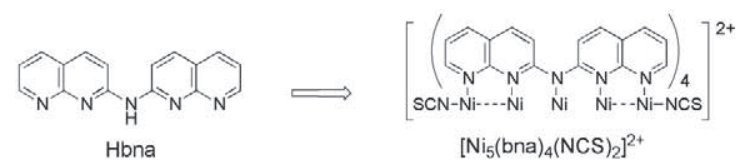

$\left[\mathrm{Ni}_{5}(\mathrm{bna})_{4}(\mathrm{NCS})_{2}\right]^{2+}$

Fig. 5 The ligand $\mathrm{Hbna}$ and a related mixed-valent pentanickel string compound.

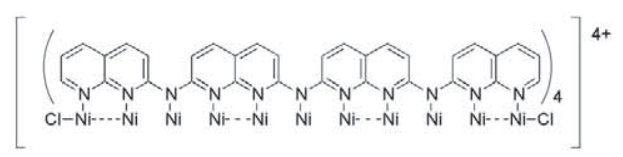

Fig. 6 The longest metal string complex, $\left[\mathrm{Ni}_{11}(\text { tentra })_{4} \mathrm{Cl}_{2}\right]^{4+}$.

\subsection{Heteronuclear metal string complexes (HMSCs)}

In addition to MV nickel string complexes, another important recent breakthrough in this field is the development of heteronuclear metal string complexes (HMSCs). In the early years, the linear metal frameworks of metal string complexes only consisted of identical metal ions. In order to develop new 
metal string complexes, our group presented the new concept of inserting a heterometal ion into the homonuclear metal string complexes.

Based on this idea, our group reported the compound $\left[\mathrm{CoPdCo}(\mathrm{dpa})_{4} \mathrm{Cl}_{2}\right]$ in 2007 (Scheme 8), the first heterometallic framework in the family of metal string complexes. ${ }^{26)}$ The traditional homonuclear $\left[\mathrm{Co}_{3}(\mathrm{dpa})_{4} \mathrm{Cl}_{2}\right]$ shows spin-cross over behavior. ${ }^{8 c)}$ However, the new heteronuclear $\left[\mathrm{CoPdCo}(\mathrm{dpa})_{4} \mathrm{Cl}_{2}\right]$ has two antiferromagnetically coupled Co(II) ions, which is significantly different with those observed in the $\left[\mathrm{Co}_{3}(\mathrm{dpa})_{4} \mathrm{Cl}_{2}\right]$. It indicates that the insertion of a heteronuclear metal ion in a homonuclear metal string complex indeed provides a new way of tuning its physical properties. Accordingly, two related HMSC, $\left[\mathrm{CuPdCu}(\mathrm{dpa})_{4} \mathrm{Cl}_{2}\right]$ and $\left[\mathrm{CuPtCu}(\mathrm{dpa})_{4} \mathrm{Cl}_{2}\right]$, were continuously reported. Since the central metal atom in $\left[\mathrm{Cu}_{3}(\mathrm{dpa})_{4} \mathrm{Cl}_{2}\right]^{+}$was considered as a crossing point of the superexchange pathways, the replacement in the central position of a diamagnetic $\mathrm{Cu}$ (III) by isoelectric $\mathrm{Pd}(\mathrm{II})$ and $\mathrm{Pt}(\mathrm{II})$ decreases the superexchange interaction between the two outermost $\mathrm{Cu}(\mathrm{II})$ atoms. ${ }^{27)}$
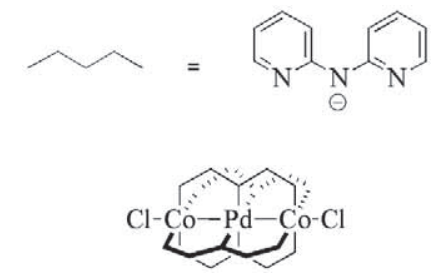

Scheme 8 The complex CoPdCo(dpa) ${ }_{4} \mathrm{Cl}_{2}$

After the successful synthesis of symmetric HMSCs, Berry and our group have reported several examples of unsymmetric HMSCs, which have $M_{A} M_{A} M_{B}$ frameworks. ${ }^{28)}$ The basic principle for synthesizing unsymmetric HMSCs is that the $M_{A} M_{A}$ pair should have strong $M_{A}-M_{A}$ bonds. For example, the $\mathrm{CrCrCo}(\mathrm{dpa})_{4} \mathrm{Cl}_{2}$ and $\mathrm{MoMoCo}(\mathrm{dpa})_{4} \mathrm{Cl}_{2}$ have quadruplebonded $\mathrm{CrCr}$ and MoMo pairs, respectively (Scheme 9). ${ }^{28 b)}$ Then these $\mathrm{M}_{\mathrm{A}} \mathrm{M}_{\mathrm{A}}$ pairs can coordinate to a different metal ion $M_{B}$, and form unsymmetric $M_{A} M_{A} M_{B}$ HMSCs.

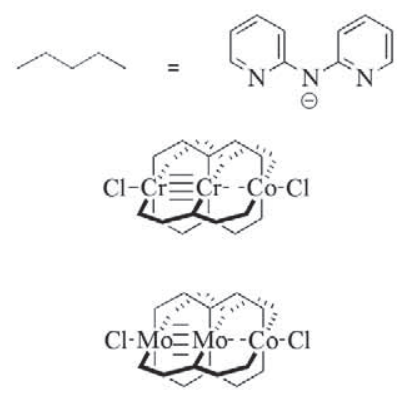

Scheme 9 Unsymmetric heteronuclear metal string complexes $\mathrm{CrCrCo}(\mathrm{dpa})_{4} \mathrm{Cl}_{2}$ and $\mathrm{MoMoCo}(\mathrm{dpa})_{4} \mathrm{Cl}_{2}$.
It is interesting to mention that the combination of heteronuclear metal ions in the linear framework is a potential approach to build bio-mimics and electronic devices. For example, the coordination sphere of $\mathrm{Fe}(\mathrm{II})$ ion in $\mathrm{CrCrFe}(\mathrm{dpa})_{4} \mathrm{Cl}_{2}$ is similar to the catalytic center of cytochromes $\mathrm{P} 450$ (Figure 7). ${ }^{28 a}$ Since the $\mathrm{CrCr}-\mathrm{Fe}$ interaction stabilizes the higher oxidation state of the Fe(II) site, the $\mathrm{CrCrFe}(\mathrm{dpa})_{4} \mathrm{Cl}_{2}$ may be a potential biomimetic model for studying high-valent iron chemistry. Furthermore, the energy gap between molecular orbitals of adjacent heterometal ions may preferentially allow the current to flow in one direction, which provides a reasonable strategy for the development of inorganic molecular rectifiers. ${ }^{28 \mathrm{~d})}$
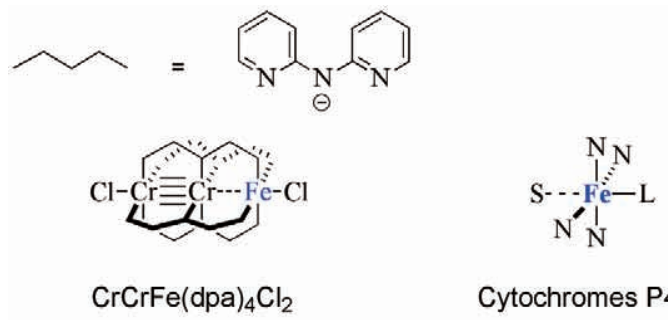

Cytochromes P450

Fig. 7 Unsymmetric metal string complexes $\mathrm{CrCrFe}(\mathrm{dpa})_{4} \mathrm{Cl}_{2}$ (left) and the catalytic center of Cytochromes P450 (right).

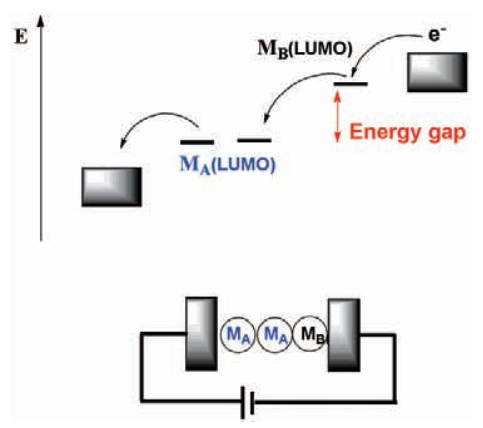

Fig. 8 The proposed mechanism for heteronuclear metal string complex as a molecular rectifier.

\section{Summary and Prospects}

Metal string complexes consist of a linear transition metal chain, which provides an excellent conducting pathway between two electrodes. By using suitable bridging ligands, numerous metal string complexes have already been synthesized and characterized in the past two decades. The studies of two new types of metal string complexes, MV Ni string complexes and heteronuclear metal string complexes, are currently the hottest topics in this field. ${ }^{8 c, 24)}$ The MV Ni string complexes do not only show great conductivity but also have high stability. ${ }^{22)}$ Those two advantages cause them to be the most important metal string complexes currently studied. 
On the other hand, heteronuclear metal string complexes are significant in fundamental research such as magnetic properties and metal-metal bonds. The $\mathrm{M}_{A} \mathrm{M}_{\mathrm{A}} \mathrm{M}_{\mathrm{B}}$ frameworks in HMSCs are also expected to have potential applications as biomimetic models and inorganic rectifiers. ${ }^{28)}$ While the study of metal string complexes is now a fairly mature field, it continues to provide interesting new results that are often surprising. Finally, whilst inorganic materials dominate conventional solid-state electronics, to date, molecular electronics research has almost exclusively focused on the properties of organic systems. Therefore, a major future challenge in this field is to use metal string complexes for fabricating molecular devices.

\section{Acknowledgements}

The authors acknowledge the National Science Council and the Ministry of Education of Taiwan for financial support. Isiah thanks Mr. Jamie Cameron (University of Glasgow) for his valuable suggestions for this article.

\section{References}

1) The 1997 National Technology Roadmap for Semiconductors (SEMATCH, Austin, TX, 1997).

2) a) J. M. Tour, Acc. Chem. Res. 33, 791 (2000); b) M. A. Reed, J. M. Tour, Sci. Am. 282, 86 (2000); c) Atomic and Molecular Wires, vol. 341 (Eds.: C. Joachim, S. Roth), NATO Applied Science, Kluwer, Boston, 1997; d) Molecular Electronics: Science and Technology, Vol. 852 (Eds.: A.Aviram, M. Ratner), Ann. N. Y. Acad. Sci. 1998; e) C. Joachim, J. K. Gimzewski, A. Aviram, Nature 408, 541 (2000).

3) a) A. Aviram, M. A. Ratner, Chem. Phys. Lett. 29, 277 (1974); b) J. K. Gimzeski, C. Joachim, Science 283, 1683 (1999); c) Introduction to Molecular Electronics (Eds.: M. C. Petty, M. R. Bryce, D. Bloor) Oxiford Univ. Press, New York, 1995; d) J. R. Heath, P. J. Kuekes, G. S. Snider, R. S. Williams, Science 280, 1716 (1998).

4) a) J. F. Berry, F. A. Cotton, P. Lei, T. Lu, C. Murillo, Inorg. Chem. 42, 3534 (2003) and the references therein; b) Molecular Wires: From Design to Perspectives: Top. Curr. Chem. 2005, 257 (Ed.: L. De Cola).

5) K. Krogmann, Angew. Chem. Int. Ed. Engl. 8, 35 (1969).

6) a) K. Krogmann, Angew. Chem. Int. Ed. Engl. 81, 10 (1969); b) J. M. Williams, Adv. Inorg. Chem. Radiochem. 26, 235 (1983); c) J. R. Ferraro, J. M. Williams, Introduction to Synthetic Electrical Conductors, Academic Press, San Diego, 1987, chap 4; d) J. K. Bera, K. R. Dunbar, Angew. Chem. Int. Ed. 41, 4453 (2002).

7) a) S. Roth, One-Dimensional Metals, VCH, New York, 1995; b) Extended Linear Chain Compounds, Vols. 1-3 (Ed.: J. S. Miller), Plenum, New York, 1982.

8) a) L.-G. Zhu and S.-M. Peng, Wuji Huaxue Xuebao, 18, 117 (2002); b) C.-Y. Yeh, C.-C. Wang, C.-h. Chen and S.-M. Peng, in Nano Redox Sites: Nano-Space Control and its Applications, T. Hirao, Ed.; Springer: Berlin, 2006, Chapter 5, pp. 85-117; c) J .F. Berry, Structure and Bonding, 136, 1 (2010).

9) T.J. Hurley, M.A. Robinson, Inorg. Chem. 7, 33 (1968).
10) a) S. Aduldecha, B. Hathaway, J. Chem. Soc. Dalton Trans. 993 (1991); b) G. J. Pyrka, M. El-Mekki, A. A. Pinkerton, J. Chem. Soc., Chem. Commun. 84 (1991); c) L.-P. Wu, P. Field, T. Morrissey, C. Murphy, P. Nagle, B. Hathaway, C. Simmons, P. Thornton, J. Chem. Soc. Dalton Trans. 3835 (1990).

11) a) C.-C. Wang, W.-C. Lo, C.-C. Chou, G.-H. Lee, J.-M. Chen, S.-M. Peng, Inorg. Chem. 37, 4059 (1998); b) S.-J. Shieh, C.-C. Chou, G.H. Lee, C.-C. Wang, S.-M. Peng, Angew. Chem. Int. Ed. Engl. 36, 56 (1997); c) H.-C. Chang, J.-T. Li, C.-C.Wang, T.-W. Lin, H.-C. Lee, G.-H. Lee, S.-M. Peng, Eur. J. Inorg. Chem. 1243 (1999); d) F. A. Cotton, L. M. Daniels, T. Lu, C. A. Murillo, X. Wang, J. Chem. Soc. Dalton Trans. 517 (1999); e) C.-Y. Yeh, C.-H. Chou, K.-C. Pan, C.-C. Wang, G.-H. Lee, Y. O. Su, S.-M. Peng, J. Chem. Soc. Dalton Trans. 2670 (2002).

12) a) S.-Y. Lai, T.-W. Lin, Y.-H. Chen, C.-C. Wang, G.-H. Lee, M. Yang, M. Leung, S.-M. Peng, J. Am. Chem. Soc. 121, 250 (1999); b) Y.-H. Chen, C.-C. Lee, C.-C. Wang, G.-H. Lee, S.-Y. Lai, F.-Y. Li, C.-Y. Mou, S.-M. Peng, Chem. Commun. 1667 (1999).

13) S.-M. Peng, C.-C. Wang, Y.-L. Jang, Y.-H. Chen, F.-Y. Li, C.-Y. Mou, M.-K. Leung, J. Magn. Magn. Mater. 209, 80 (2000).

14) Multiple Bond between Metal Atoms, $3^{\text {rd }}$ ed. (Eds.: F.A. Cotton, C.A. Murillo, R.A. Walton), Springer, New York (2005).

15) a) M.-M. Rohmer, M. Bénard, J. Am. Chem. Soc. 120, 9372 (1998); b) M.-M. Rohmer, A. Strich, M. Bénard, J.-P. Malrieu, J. Am. Chem. Soc. 123, 9126 (2001); c) N. Benbellat, M.-M. Rohmer, M. Bénard, Chem. Commun. 2368 (2001); d) M.-M. Rohmer, M. Bénard, Chem. Soc. Rev. 30, 340 (2001); e) M.-M. Rohmer, M. Bénard, J. Cluster Sci. 13, 333 (2002); f) P. Kiehl, M.-M. Rohmer, M. Bénard, Inorg. Chem. 43, 3151 (2004).

16) Clérac, R.; Cotton, F. A.; Dunbar, K. R.; Murillo, C. A.; Pascual, I.; Wang, X. Inorg. Chem. 38, 2655 (1999).

17) D. A. Pantazis, C. A. Murillo and J. E. McGrady, J. Am. Chem. Soc. 128, 4128 (2006).

18) a) C.-K. Kuo, I. P.-C. Liu, C.-Y. Yeh, C.-H. Chou, T.-B. Tsao, G.-H. Lee and S.-M. Peng, Chem. Eur. J. 13, 1442 (2007); b) J. F. Berry, F. A. Cotton, T. Lu, C. A. Murillo, B. K. Roberts, X. Wang J. Am. Chem. Soc. 126, 7082 (2004).

19) a) J. F. Berry, F. A. Cotton and C. A. Murillo, Organometallics 23, 2503 (2004); b) C.-K. Kuo, J.-C. Chang, C.-Y. Yeh, G.-H. Lee, C.C. Wang and S.-M. Peng, Dalton Trans. 3696 (2005).

20) a) S.-Y. Lin, I.-W. P. Chen, C-h. Chen, M.-H. Hsieh, C.-Y. Yeh, T.-W. Lin, Y.-H. Chen, S.-M. Peng, J. Phys. Chem. B 108, 959 (2004); b) I-W. P. Chen, M.-D. Fu, W.-H. Tseng, J.-H. Yu, S.-H. Wu, C.-J.; Ku, C.-h.; Chen, S.-M. Peng, Angew. Chem., Int. Ed. 45, 5814 (2006).

21) a) C.-H. Chien, J.-C. Chang, C.-Y. Yeh, L.-M. Fang, Y. Song, S.-M. Peng, Dalton Trans. 3249 (2006); b) C.-H. Chien, J.-C. Chang, C.Y. Yeh, G.-H. Lee, L.-M. Fang, S.-M. Peng, Dalton Trans. 2106 (2006).

22) I. P.-C. Liu, M. Bénard, H. Hasanov, I-W. P. Chen, W.-H. Tseng, M.-D. Fu, M.-M. Rohmer, C.-h. Chen, G.-H. Lee, S.-M. Peng, Chem. Eur. J. 13, 8667 (2007).

23) A. Bencini, E. Berti, A. Caneschi, D. Gatteschi, E. Giannasi, I. Invernizzi, Chem. Eur. J. 8, 3660 (2002).

24) I. P.-C. Liu, W.-Z. Wang, S.-M. Peng, Chem. Commun. 4323 (2009).

25) R. H. Ismayilov, W.-Z. Wang, G.-H. Lee, C.-Y. Yeh, S.-A. Hua, Y. Song, M.-M. Rohmer, M. Bénard, S.-M. Peng, Angew. Chem. Int. Ed. 50, 2045 (2011).

26) M.-M. Rohmer, I. P.-C. Liu, J.-C. Lin, M.-J. Chiu, G..-H. Lee, M. Bénard, X. López, S.-M. Peng, Angew. Chem., Int. Ed. 46, 3533 (2007). 
27) I. P.-C. Liu, G.-H. Lee, S.-M. Peng, M. Bénard, M.-M. Rohmer, Inorg. Chem. 46, 9602 (2007).

28) a) M. Nippe, J. F. Berry, J. Am. Chem. Soc. 129, 12684 (2007); b) M. Nippe, E. Victor, J. F. Berry, Eur. J. Inorg. Chem. 5569 (2008); c)
G.-C. Huang, M. Bénard, M.-M. Rohmer, L.-A. Li, M.-J. Chiu, C.Y. Yeh, G.-H. Lee, S.-M. Peng, Eur. J. Inorg. Chem. 1767 (2008); d) I. P.-C. Liu, C.-H. Chen, C.-F. Chen, G.-H. Lee, S.-M. Peng, Chem. Commun. 577 (2009).

\section{Profile}

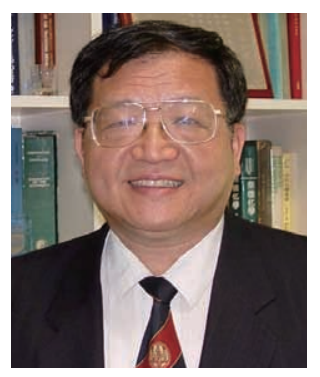

Shie-Ming Peng received his BS from National Taiwan University in 1970, and his Ph.D. from University of Chicago in 1975. After finishing a postdoctoral fellowship at Northwestern University, he became an Associate Professor (1976-80) and a Full Professor (1980) of National Taiwan University. He was the Chairman of the Department of Chemistry (1987-1990) and the Vice President of the National Taiwan University (1999-2002). He also served as the President of the Chemical Society Located in Taipei (2001-2002). In 1998, he was elected as the Academician of Academia Sinica. He was also elected as a member of TWAS (The Third World Academy of Sciences) in 2004. He received TWAS prize in chemistry (2002), Taiwan-French Science Prize (2008) and Japan Society of Coordination Chemistry International Award (2011). His research is currently centered on developing metal string complexes and investigating their applications in molecular electronics.

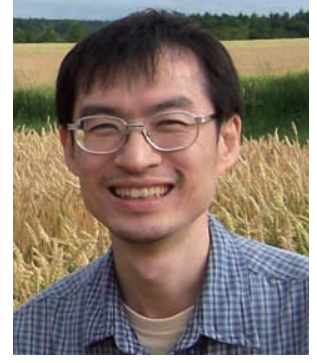

Chun-hsien Chen obtained his B.S. degree in 1986 from National Sun Yat-Sen University and Ph.D. degree in 1993 from the University of Illinois at Urbana-Champaign. After spending two years as a postdoctoral associate at the University of North Carolina at Chapel Hill, he joined the Department of Chemistry at National Sun Yat-Sen University. He moved to National Tsing Hua University in 2000 as an Associate Professor in chemistry and was promoted to Full Professor in 2001. Beginning from August 2006, he joined the National Taiwan University. His research interests involve $I-V$ characteristics of single molecules, scanning probe microscopy, surface modification and characterization, nanoparticles as sensing reporters, electrochemistry, and solid-liquid interfacial phenomena. He was a recipient of the Chinese Chemical Society Young Chemist Award (2001), NTHU Young Investigator Award (2002), Outstanding Research Award from NSC (National Science Council, 2008), and Y. Z. Hsu Scientific Paper Award (2009).

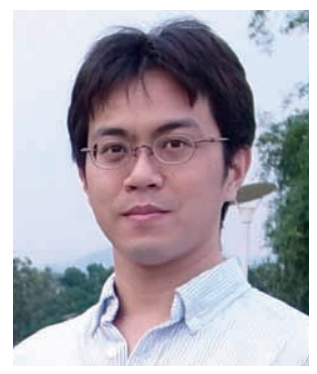

Isiah Po-Chun Liu received his BS from Nation Chung-Hsing University in 2001 and his MS from National Tsing Hua University in 2003 (advisor: Professor Sunney I. Chan). After being a research assistant for two years at Academia Sinica, he went to National Taiwan University and received his Ph.D. in 2008 under the direction of Professor Shie-Ming Peng. During his Ph.D. studies, he spent six months working in a quantum chemistry laboratory at the Université de Strasbourg (France) under the supervision of Dr. M. Bénard and Professor M.-M. Rohmer. After postdoctoral work with Professors Tong Ren (Purdue University, USA) and A. C. Filippou (Universität Bonn, Germany), he joined the research group of Professor H. Oshio (Tsukuba University, Japan) as a JSPS (Japan Society for the Promotion of Science) special researcher in 2011. His research interests include molecular magnetism, theoretical chemistry and spectroscopy. 